\title{
HbA1c levels in patients of acute decompensated heart failure
}

\author{
Ravi Shekhar ${ }^{1}$, Biju Govind², N V S Chowdary 3 , Sadhna Sharma ${ }^{4}$, R John Satish², \\ S Vidya Desai ${ }^{3}$, V Siva Prabodh ${ }^{3}$, Ahmad Nadeem Aslami ${ }^{5}$
}

${ }^{1}$ Associate Professor, Department of Biochemistry, Indira Gandhi Institute of Medical Sciences, Patna, Bihar, ${ }^{2}$ Professor, Department of Cardiology, NRI Medical College, Mangalagiri, Guntur, ${ }^{3}$ Professor, Department of Biochemistry, NRI Medical College, Mangalagiri, Guntur, ${ }^{4}$ Professor, Department of Medicine, NRI Medical College, Mangalagiri, Guntur, ${ }^{5}$ Assistant Professor, Department of Community Medicine, Narayan Medical College \& Hospital, Sasaram

\section{A B STR A C T}

Background: Hospitalization for Heart Failure (HF) is increasing in India. Diabetes Mellitus (DM) is closely related to $\mathrm{HF}$. $\mathrm{Hb} 1 \mathrm{Ac}$ is an index of metabolic control of DM. Hb1 Ac is associated with increased risk of Acute Decompensated Heart Failure (ADHF). The relation between $\mathrm{Hb} 1 \mathrm{Ac}$ and $\mathrm{ADHF}$ is less well defined. Aims and Objectives: The aim of the study was to find out the prevalence of ADHF among patients admitted for cardiac complaints and to investigate $\mathrm{Hb} 1 \mathrm{Ac}$ levels in confirmed patients. Materials and Methods: A hospital based study was conducted at NRI Heart Centre, NRI General Hospital, Guntur from May to July 2013 after institutional ethical approval. All patients of ADHF were included in the study. Patients were analysed for $\mathrm{HbA} 1 \mathrm{c}$. Results: Out of 1147 patients admitted in Coronary Care Unit, there were 101 cases of ADHF giving a prevalence of $8.8 \%$. The mean age was found to be 54.69 years. $19.8 \%$ of the patients were of age less than 40 . There were $74.3 \%$ males and $25.7 \%$ females. The mean $\mathrm{HbA} 1 \mathrm{c}$ in non diabetic, pre-diabetic and diabetic was $5.32 \%, 6.0 \%$ and $8.45 \%$ respectively. Conclusion: Elevated $\mathrm{HbA} 1 \mathrm{c}$ is associated with increased morbidity in the heart failure and efforts should be made to treat these patients with proven therapies to lower the blood glucose levels.

Key words: HbA1c, Acute Decompensated Heart Failure (ADHF), Prevalence

\section{INTRODUCTION}

Heart failure (HF) is a growing public health issue and is also a major cause of morbidity. ${ }^{1} \mathrm{HF}$ is a major and increasing burden all over the world. ${ }^{2}$ The prevalence estimates of HF are unreliable in India because of the lack of surveillance system to adequately capture these data. The estimated prevalence of HF in India is 1.3-4.6 million with an annual incidence of 491,600-1.8 million. $^{3}$

The deteriorating clinical outcomes of patients with HF and reduced Left Ventricular ejection fraction (LVEF) may lead to Acute Decompensated Heart Failure (ADHF), where the prognosis remains poor with mortality exceeding $50 \%$ at 5 years with a high rate of rehospitalisation and this leads to increased financial burden. ${ }^{4}$
The most prevalent form of Diabetes Mellitus (DM) is type II and its incidence increase with advancing age. Insulin resistance in DM is accompanied by other cardiovascular factors - dyslipidemia, hypertension, pro-thrombotic factors, activators of multiple hormone and cytokine system, autonomic neuropathy, endothelial dysfunction and coronary artery disease (CAD). ${ }^{5,6} \mathrm{DM}$ is an important risk factor for cardiac disease. DM appears to be strongly linked to HF. It has been suggested that DM plays an important role in the pathogenesis, prognosis and response to treatment of $\mathrm{HF}^{7}$

Fasting glucose is an accepted parameter for assessing glycemic control. Glycemic control can also be measured by glycated haemoglobin (HbA1c) which indicates the ambient plasma glucose concentration over the preceding 2 to 3 months. Raised HbA1c level indicates poor 
metabolic control and eventually lead to micro vascular complications. ${ }^{7-9}$

American Diabetes Association (ADA) and Japan Diabetes Society recommended using $\mathrm{HbA} 1 \mathrm{c}$ as a criterion for diagnosing diabetes. HbA1c offers several diagnostic advantages compared to fasting glucose and should be considered an established marker of long term glycemic control in patients with diabetes mellitus. ${ }^{10}$

The study was performed to find out the prevalence of ADHF among patients admitted for cardiac complaints and to investigate Hb1 Ac levels in confirmed patients.

\section{MATERIALS AND METHODS}

The study was a hospital based descriptive clinical study conducted in collaboration with Cardiology, Medicine and Biochemistry department at NRI Heart Centre, NRI General Hospital, Guntur. The study period was from May to July 2013.

All patients admitted in Coronary Care Unit were included in the study. Conventional 2D echocardiography (ECHO) was performed. Patients with ejection fraction $<35 \%$ were selected for the study. Two cardiologists independently checked ejection fraction for all the patients and on the basis of sign and symptoms confirmed the diagnosis of ADHF. Data was acquired with a $3.5 \mathrm{MHz}$ transducer (S3) in the parasternal (long and short-axis views) and apical views (two- and four- chamber and apical long axis views). Left ventricular dimensions were calculated from the standard M-mode images at the parasternal long-axis views. The left ventricular end-diastolic and end-systolic volumes were measured from the apical two- and four- chamber views and left ventricular ejection fraction was calculated using the Simpson's rule. ${ }^{11}$ Treatment was initiated based on the clinical condition and physicians' judgement. Patients with valvular heart disease, acute coronary syndrome, recent pregnancy, advanced renal failure, infective endocarditis and systemic infection presenting with heart failure were excluded.

Patients were also analysed for HbA1c. $2 \mathrm{ml}$ of venous blood sample was collected in EDTA vaccutainer from each patient and was measured on an automated high performance liquid chromatography analyzer. Two levels of diabetic control was estimated subsequently and analysed daily to check for the quality of the report. The patients were classified into 3 groups on the basis of HbA1c values as recommended by ADA 2010 guidelinesas non diabetic $(<5.6 \%)$, pre-diabetic $(5.7 \%-6.4 \%)$ and diabetic $(>6.5 \%) .^{12}$
Study was approved by institutional ethics committee and informed consent obtained from all patients. Data was entered in MS Excel and analyzed by the statistical package SPSS software, version 16.0. Descriptive and inferential statistics were applied (percentages and $\mathrm{Z}$ test). The values of $P$ were kept significant at the level of 0.05 .

\section{RESULTS}

Of the total 1147 patients admitted in cardiac coronary unit, 101 patients had been diagnosed as ADHF with age ranging from 22 to 85 years. There were 75 males $(74.3 \%)$ and 26 females $(25.7 \%)$. ADHF prevalence was $8.8 \%$, calculated as the proportion of the study sample.

The mean age was found to be 54.69 years (SD $=13.62)$, and median was 56 years. As per age group, most of the patients were of age more than 60 years $(33.66 \%)$, although young patients were also found in the study $(<30 \mathrm{yrs}-5.9 \%$, 31-40 yrs-13.8\%) (Figure 1).

The mean age of non diabetic, pre-diabetic and diabetic group were $46.9(\mathrm{SD}=4.5), 50.6(\mathrm{SD}=10.2)$ and $58.4(\mathrm{SD}=11.4)$ years respectively. The mean $\mathrm{HbA1} \mathrm{c}$ in non diabetic, pre-diabetic and diabetic was $5.32 \%(\mathrm{SD}=0.27)$, $6.0 \%(\mathrm{SD}=0.23)$ and $8.45 \%(\mathrm{SD}=1.63)$ respectively. $z$ test of 2 proportions was used to analyze the difference in the proportions of heart failure cases in different groups of HbA1c (Table 1 and Figure 2).

\section{DISCUSSION}

The study indicated the prevalence of $8.8 \%$ for ADHF. In PRICE study it was shown that the prevalence was $6.8 \%$ of the population aged 45 or over in Congestive Heart Failure. ${ }^{13}$ In the study, heart failure incidence rate increased with age and was found higher in diabetes than in non-diabetes as observed in other studies. ${ }^{14,15}$ Studies suggested that improved glycaemic control was associated with reduced cardiovascular events, though not statistically significant. ${ }^{16,17}$ Diabetes and heart failure often coexist and is associated with complications and increased hospitalization. ${ }^{18}$






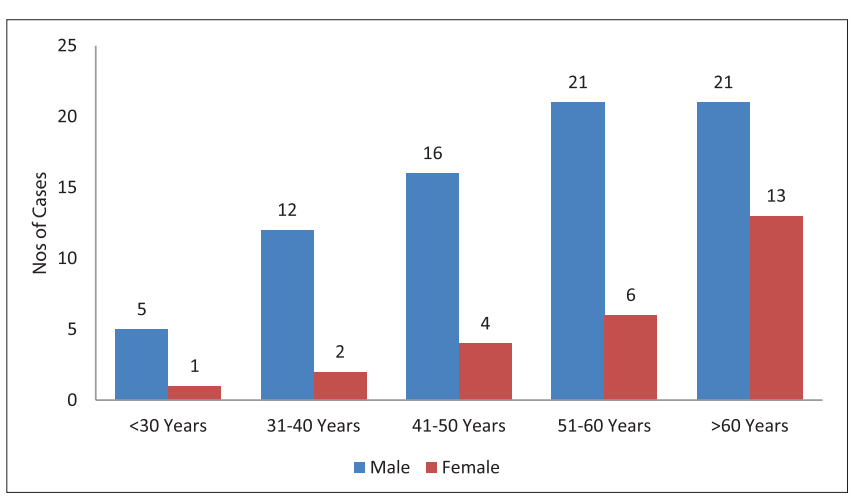

Figure 1: Age and sex distribution of HF patients



Figure 2: Acute decompensated heart failure patients classified on $\mathrm{HbA1c}$ values

In the study, the diabetics formed a major group. A large systematic review of evidence done earlier which examined the risk of cardiovascular disease associated with impaired fasting glucose (IFG) and impaired glucose tolerance (IGT) according to WHO criteria could not arrive at a definite conclusion and suggested further studies to classify the relationship between pre-diabetic and cardiovascular disease. ${ }^{19}$ A population based cohort study done among old adults could not find any evidence that pre-diabetes is an independent risk factor for incident heart failure. ${ }^{20}$ However, IFG, IGT or pre-diabetic HbA1c levels not studied extensively regarding prevalence of severe heart failure. IFG and IGT are risk factors for future diabetes as well as for cardiovascular disease. ${ }^{16}$ The CHARM program data analysis also showed that HbA1c is strong and independent risk factor for cardio-vascular events including cardio-vascular death and hospitalization due to heart failure, but did not study pre-diabetic population..$^{21}$ In the present study, the prevalence of ADHF in pre-diabetic was significantly higher when compared to non-diabetic population. Similarly, a significant difference was observed between pre-diabetic and diabetic groups with a larger incidence of heart failure in diabetic population. Thus, with this study data it clearly suggests that pre-diabetes is a strong risk factor for ADHF though less than diabetes. This suggests that pre-diabetes is not a innocent condition heralding overt diabetes, but itself associated with significant changes in metabolic milieu. Accelerated atherosclerosis and other mechanism producing diabetes myocardiopathy could be at work even in pre-diabetic stage.

Many studies are consistent, but do not prove the concept that improved glycaemic control might reduce cardiovascular risk in patients with diabetes. In the ACCORD (The Action to Control Cardiovascular Risk in Diabetes Study Group) study, intensive glucose lowering aimed to decrease $\mathrm{HbA} 1 \mathrm{c}$ below $6 \%$ resulted in unexpected increased mortality in patients who were on intensive glucose control compared to those receiving standard care. ${ }^{22}$ UKPDS (United Kingdom Prospective Diabetes Study) did not prove that reducing blood glucose by intensive therapy reduces cardiovascular events. ${ }^{17}$ In this study, a linear relationship existed for $\mathrm{HbA1} \mathrm{c}$ in patients of ADHF. Aguilar et al. study showed that the relationship between mortality in established heart failure patients and $\mathrm{HbA1c}$ was U-shaped. The mortality was seen to be least in the patients with modest glycaemic control $(7.1 \%<$ $\mathrm{HbA} 1 \mathrm{c} \leq 7.8 \%)^{23}$

The present study has some limitation because it has been done in a small group of population admitted in the hospital due to ADHF. Follow up of the patients after initial therapeutic intervention including various classes of drugs known to decrease morbidity and mortality in heart failure has not been done. Further studies are required to evaluate the possibility of treatment intervention in pre-diabetic and uncontrolled diabetes with proper control of glycemic index with advanced compensated heart failure to decrease the morbidity and mortality.

\section{CONCLUSION}

The elevated Hb1Ac has a significant role in increasing the risk for ADHF. Pre-diabetics, although considered harmless regarding ADHF hospitalization must be monitored regularly for $\mathrm{Hb} 1 \mathrm{Ac}$ value and considered for glucose lowering therapy. Future studies should be designed to confirm these findings and expand on potential mechanisms contributing to the increased hazards of ADHF.

\section{REFERENCES}

1. Bauters C, Lamblin N, Mc Fadden EP, Van Belle E, Millaire A and de Groote P. Influence of diabetes mellitus on heart failure risk and outcome. Cardiovasc Diabetol 2003;2:1.

2. Lloyd-Jones DM, Larson MG, Leip EP, Beiser A, D'Agostino RB, Kannel WB, et al. Lifetime risk for developing congestive 
heart failure: the Framingham Heart Study. Circulation 2002; 106:3068-3072.

3. Huffman MD and Prabhakaran D. Heart failure: epidemiology and prevention in India. Natl Med J India 2010; 23:283-288.

4. Yeh JK, Hsiao YC, Jian CR, Wang CH, Wen MS, Kuo CT, et al Comparison of Baseline versus Post treatment Left Ventricular Ejection Fraction in Patients with Acute Decompensated Heart Failure for Predicting Cardiovascular Outcome: Implications from Single-Center Systolic Heart Failure Cohort. PloS ONE 2016; $11: \mathrm{e} 0145514$.

5. Grundy SM, Benjamin IJ, Burke GL, Chait A, Eckel RH, Howard BV, et al. Diabetes and cardiovascular disease a statement for healthcare professionals from the American Heart Association. Circulation 1999; 100:1134-1146.

6. Wang J, Song Y, Wang Q, Kralik PM and Epstein PN. Causes and characteristics of diabetic cardiomyopathy. Rev Diabetic Stud 2006; 3:108-117.

7. Jabir MF and Lang C. Glycemic control \& heart failure development importance of health promotion in the diabetic patient. SUMJ 2012:1; 63-75.

8. Iribarren C, Karter AJ, Go AS, Ferrara A, Liu JY, Sidney S, et al. Glycemic control and heart failure among adult patients with diabetes. Circulation 2001; 103:2668-2673.

9. Ikeda F, Doi Y, Ninomiya T, Hirakawa Y, Mukai N, Hata J, et al. Haemoglobin A1c even within non-diabetic levels a predictor of cardiovascular disease in a general Japanese population: the Hisayama study. Cardiovasc Diabetol 2013; 12:164.

10. Ikeda N, Lijima R, Hara H, Moroi M, Nakamura M and Sugi K. Glycated haemoglobin is associated with the complexity of coronary artery disease, even in non-diabetic adults. J Atheroscler Thromb 2012; 19:1066-1072.

11. Lang RM, Bierig M, Devereux RB, Flachskampf FA, Foster E, Pellikka PA, et al. American Society of Echocardiography's nomenclature and standards committee; task force on chamber quantification; American college of cardiology echocardiography committee; American heart association; European association of echocardiography, European society of cardiology. Eur J Echocardiogr 2006; 7:79-108.

12. American Diabetes Association. Standards of medical care in diabetes. Diabetes Care 2010; 33:S11-S61.

13. Anguita Sanchez M, Crespo Leiro MG, de Teresa Galvan E, Jimenez Navarro M, Alonso-Pulpon L, Muniz Garcia J, et al.
Prevalence of heart failure in the Spanish general population aged over 45 years. The PRICE Study. Res Esp Cardiol 2008; 61:1041-1049.

14. Nichols GA, Gullion CM, Koro CE, Ephross SA and Brown JB. The incidence of congestive heart failure in type 2 diabetes: an update. Diabetes Care 2004; 27:1879-1884.

15. Lazzarini V, Mentz RJ, Fiuzat M, Metra M and O' Connor CM. Heart failure in elderly patients: distinctive features and unresolved issues. Eur J Heart Fail 2013; 15:717-723.

16. American Diabetes Association. Diagnosis and classification of diabetes mellitus. Diabetes Care 2004; 27:S5-S10.

17. American Diabetes Association. Implications of United Kingdom prospective diabetes study. Diabetes Care 2002; 25:S28-S32.

18. Preiss D, Zetterstrand S, McMurray JJV, Ostergren J, Michelson EL, Granger CB, et al. Predictors of development of diabetes in patients with chronic heart failure assessment of reduction in mortality and morbidity (CHARM) program. Diabetes Care 2009; 32:915-920.

19. Ford ES, Zhao G and Li C. Pre-diabetes and the risk for cardiovascular disease: a systematic review of the evidence. J Am Coll Cardiol 2010; 55:1310-1317.

20. Deedwania P, Patel K, Fonarow GC, Desai RV, Zhang Y, Feller MA, et al. Prediabetic is not an independent risk factor for incident heart failure, other cardiovascular events or mortality in older adults: findings from a population-based cohort study. Int J Cardiol 2013; 168:3616-3622.

21. Gerstein HC, Swedberg K, Carlsson J, Mcmurray JJ, Michelson EL, Olofsson B, et al. CHARM program investigators. The haemoglobin A1c level as a progressive risk factor for cardiovascular death, hospitalization for heart failure, or death in patients with chronic heart failure: an analysis of the Candesartan in heart failure: Assessment of reduction in mortalit and morbidity (CHARM) program. Arch Intern Med 2008; 168:1699-1704.

22. Gerstein HC, Miller ME, Byington RP, Goff DC, Bigger JT, Buse JB, et al. Effects of intensive glucose lowering in type 2 disease. Action to control cardiovascular risk in diabetes study group. N Engl J Med 2008; 358:2545-2559.

23. Aguilar D, Bozkurt B, Ramasubbu Kand Deswal A. Relationship of haemoglobin $\mathrm{A} 1 \mathrm{C}$ and mortality in heart failure patients with diabetes. J Am Coll Cardiol 2009; 54:422-428. 